IZA DP No. 8876

The Role of Education and Family Background in Marriage, Childbearing and Labor Market Participation in Senegal

Francesca Marchetta

David E. Sahn

February 2015 


\title{
The Role of Education and Family Background in Marriage, Childbearing and Labor Market Participation in Senegal
}

\author{
Francesca Marchetta \\ CERDI, University of Auvergne \\ and CNRS \\ David E. Sahn \\ Cornell University, \\ IZA and CERDI
}

Discussion Paper No. 8876
February 2015

IZA

P.O. Box 7240

53072 Bonn

Germany

Phone: +49-228-3894-0

Fax: +49-228-3894-180

E-mail: iza@iza.org

\begin{abstract}
Any opinions expressed here are those of the author(s) and not those of IZA. Research published in this series may include views on policy, but the institute itself takes no institutional policy positions. The IZA research network is committed to the IZA Guiding Principles of Research Integrity.

The Institute for the Study of Labor (IZA) in Bonn is a local and virtual international research center and a place of communication between science, politics and business. IZA is an independent nonprofit organization supported by Deutsche Post Foundation. The center is associated with the University of Bonn and offers a stimulating research environment through its international network, workshops and conferences, data service, project support, research visits and doctoral program. IZA engages in (i) original and internationally competitive research in all fields of labor economics, (ii) development of policy concepts, and (iii) dissemination of research results and concepts to the interested public.
\end{abstract}

IZA Discussion Papers often represent preliminary work and are circulated to encourage discussion. Citation of such a paper should account for its provisional character. A revised version may be available directly from the author. 


\begin{abstract}

\section{The Role of Education and Family Background in Marriage, Childbearing and Labor Market Participation in Senegal ${ }^{*}$}

This paper examines the role of education and family background on age at marriage, age at first birth, and age at labor market entry for young Senegalese women. We use a multipleequation framework that allows us to account for the endogeneity that arises from the simultaneity of the four decisions that we model. Our results highlight the importance of a woman's own education in delaying marriage, and that the relationship between her education and the timing of childbearing and of entering the labor market mainly operates through the influence of schooling decisions on the age at marriage. We show that marriage and motherhood decisions are interrelated and that the timing of first birth strongly depends on the duration of marriage. We also shed light on the composite influence of parental education and death shocks on all the outcomes we examine.
\end{abstract}

JEL Classification: $\quad 012,125, \mathrm{~J} 12, \mathrm{~J} 13$

Keywords: multiple equations, duration models, unobserved heterogeneity, Senegal

Corresponding author:

David E. Sahn

Cornell University

B16 MVR Hall

Ithaca, NY 14853

USA

E-mail: David.Sahn@cornell.edu

\footnotetext{
This document is an output from a project funded by the UK Department for International Development (DFID) and the Institute for the Study of Labor (IZA) for the benefit of developing countries. The views expressed are not necessarily those of DFID or IZA.

The authors are grateful to the editor and to four anonymous referees for their insightful comments and suggestions; we also thank Simone Bertoli, Peter Glick, Chris Handy, Stan Panis, Paul Schultz, Anne Viallefont, and the participants at the Population Association of America 2012 Annual Meeting, at the 2013 INFER Annual Conference, at the XXXèmes Journées de Microéconomie Appliquée, and at seminar presentations at CERDI, Cornell University, and the African Development Bank for the comments they gave us. This paper benefited from the financial support of the FERDI (Fondation pour les études et recherches sur le développement international), and it was supported by the Agence Nationale de la Recherche of the Government of France through the program "Investissements d'avenir" ANR-10-LABX-14-01. The usual disclaimers apply.
} 


\section{Introduction}

The decisions that young individuals and their families make regarding transitions from school into work, marriage, and parenthood can produce long-lasting effects on their opportunities and well-being. For young women, in particular, schooling duration may affect the timing of other key transitions, such as their age at marriage and at first birth, and hence also their ability to engage in remunerative work.

This paper investigates the complex interrelationships between these transitions, with a particular focus on the influence of education on the timing of marriage and childbearing, and on the ensuing effects on labor market participation. We emphasize the role of family background in shaping these intertwined critical life-course decisions.

We use a rich survey, namely the Household Survey on Education and Welfare in Senegal (henceforth EMBS 2003), conducted in 2003, that provides data on 2,668 Senegalese women aged between 15 and 30. Senegalese women have significantly lower educational achievements than men, and likewise, age at marriage and first birth is low, making the analysis of these key transitions particularly important (US Department of State 2009).

The literature, which employs a variety of methodological approaches, has established the existence of a negative relationship between education and fertility (see, inter alia, Osili and Long 2008; Baird, Chirwa, McIntosh and Özler 2010; Baird, McIntosh and Özler 2011; Duflo, Dupas and Kremer 2012; Breierova and Duflo 2004; Fafchamps and Shilpi 2014). ${ }^{1}$ Several factors can explain this negative relationship: notably, a higher level of education increases the opportunity cost of childbearing (Becker 1981), improves child health and reduces child mortality (Schultz 1994), strengthens the knowledge of contraceptive methods (Rosenzweig and Schultz 1985), and increases female bargaining power about fertility decisions (Mason 1986). 
The relationship between fertility and female labor supply has also been clearly established, notwithstanding the methodological difficulties in empirically identifying this effect (see, inter alia, Hotz and Miller 1988; Rosenzweig and Shultz 1985; Bailey 2006; Kim and Aassve 2006; Angrist and Evans 1998; Chun and Oh 2002). The analysis of how the timing of marriage is related to the transitions into motherhood and work has received more limited attention in the literature. Some of the studies on the determinants of labor supply decisions, for instance, analyze the effect of fertility on labor supply using a sample of married woman, or treat marriage as exogenous (Assaad and Zouari, 2003). However, recent findings suggest that the impact of a higher level of education on fertility is mostly driven by delaying age at marriage (Duflo et al. 2012; Kirdar, Tayfur and Koç 2009). These results are in line with the earlier findings by Brien, Lillard and Waite (1999) and Brien and Lillard (1994), who show that women make simultaneous choices regarding childbearing and marriage, that education significantly delays the age at marriage, and that the increase in the age at first conception is due to the delayed marriage.

In this paper, we jointly estimate the determinants of education, age at marriage, age at first birth and age at entry in the labor market using a multiple equation framework. ${ }^{2}$ Differences in the characteristics of the dependent variable inform the choice of the models that are used to estimate each of the four equations: an ordered probit model for the number of completed years of schooling, while hazard models are used to analyze the determinants of the other three outcomes. The estimation of the effects that each of these choices exerts on the others poses analytical challenges that arise from the need to address their endogeneity and to account for unobserved heterogeneity. We assume that there are common factors that influence these four choices. Some of these factors, such as parental education, household wealth, and characteristics of the place of residence are observed, while others, which we can label as women's preferences, are unobservable. We therefore identify the covariance matrix 
of unobserved heterogeneity components under the assumption that sisters share identical heterogeneity components for each equation, as in Brien and Lillard (1994). Moreover, we rely on exclusion restrictions: we identify the completed years of education using detailed retrospective information on local schools and the age at marriage through the use of information on the tightness marriage market. We use the information on the availability and timing of the introduction of family planning programs at the community level in order to identify the age at first childbearing. Finally, we use the data we collected on shocks that are expected to affect the local labor market to identify the decision to enter the labor market. In all these cases, we rely on retrospectively collected data, mostly derived from school and community surveys that complement the information contained in the main household survey. Although we are comfortable with these exclusion restrictions, they can be considered largely as "overidentifying restrictions," as emphasized by Brien et al. (1999, 540) and discussed further below.

Our results highlight the importance of one's own education in delaying marriage, and that the relationship between education and the risk of childbearing and of entering the labor market operates mainly through the influence of schooling decisions on the age at marriage. We show that marriage and motherhood decisions are interrelated and that the timing of first birth strongly depends on the time elapsed since the marriage. We also shed light on the composite influence of family background and shocks on the various outcomes of interest. We highlight the role of the mother's characteristics, particularly her education, on the timing of marriage, as well as the effect of the death of a parent on the risk of beginning childbearing among the sample of young women included in our analysis.

The rest of the paper is structured as follows: Section 2 briefly reviews the literature that informs the methodological challenges of accounting for the joint nature of the decisions 
we model; Section 3 presents and discusses our empirical strategy, while Section 4 introduces the data that we use in the econometric analysis and provides the relevant descriptive statistics. Section 5 presents the results of the estimation, and Section 6 draws the main conclusions.

\section{Methodological Challenges}

The empirical estimation of the relationships between our outcomes of interest school, work, marriage and parenthood - poses substantial analytical challenges, that prior research has addressed using a wide range of methodologies. A large share of the literature simply ignores issues of endogeneity and unobserved heterogeneity, and basically estimates the associations among the outcomes of interest without proving causality. For example, there is considerable documentation of a negative association between schooling and fertility (Ainsworth et al. 1996). This, and many other similar studies, especially from Africa, have used Demographic and Health Surveys (DHS) or other cross-sectional household surveys to examine the determinants of age at marriage or age at the beginning of childbearing (see, inter alia, Mensch et al. 2005; Mahy and Gupta 2002).

To begin to deal with the fact that the four outcomes may be jointly determined, making it improper to infer causality from their association, several studies explore the relationship between two of the outcomes of interest using an instrumental variable approach. The literature that explores the impact of fertility on labor supply, for instance, often uses an instrumental variable approach to deal with the endogeneity of fertility in the participation decision. In this case, endogeneity arises from the fact that preferences for market work may induce women to have fewer children. ${ }^{3}$ The main challenge here is to find a valid instrument. Several options have been employed: the local availability and cost of contraceptive technology (Rosenzweig and Shultz 1985), the variation in state-level legislation on access to contraceptive pills (Bailey, 2006), and parental preferences for a mixed sibling-sex 
composition (Angrist and Evans 1998) or for sons (Chun and Oh 2002). ${ }^{4}$ The instrumental variable approach has been also used to examine the impact of education on fertility. For example, Osili and Long (2008) and Breierova and Duflo (2004) have used exposure to programs that involve investments in local schools as an instrument for education; similarly Chicoine (2012) and Güneş (2013) exploit policy changes that extended schooling as an instrument.

More recently, random assignment evaluation studies have been used to identify the causal effects among the relationships of interest. An example is the literature that examines the impact of education on reducing fertility. This literature uses the programs aimed at improving educational outcomes in developing countries as a mean to artificially increase the education level of a group of girls, which are then compared to a control group of girls who were not exposed to the program (Baird et al. 2010, Baird et al. 2011; Duflo et al. 2012). ${ }^{5}$ Another randomized trial explores the effect of improved employment opportunities for women on education, marriage and childbearing decisions (Jensen 2012). While the use of randomized control trials holds considerable promise and raises the bar in terms of proving causality, they remain relatively limited in terms of examining relationships such as the impact of marriage and fertility on labor market entry. One reason is that it is difficult to randomize, or even incentivize, certain behaviors of interest. There are also often long time horizons that may need to be incorporated into such trials, where prospective outcomes may need to be measured years after the intervention. In addition, while we view experimental approaches favorably and of great promise, they are largely limited to exploring the relationship between two outcomes of interest, for example, between education and fertility, rather than taking a broader look at how multiple relationships are jointly determined, as we do in this paper. 
To do this, we build upon the work of Brien and Lillard (1994), who estimate the relationships among schooling, marriage and parenthood decisions using a multiple-equation framework that allows accounting for the endogeneity and the heterogeneity that arise from the simultaneity of these three decisions. More specifically, Brien and Lillard (1994) build a sequential probit model to estimate the schooling decision and model the timing of marriage and first conception through hazard models, allowing for correlation among the heterogeneity components of the three equations. ${ }^{6}$ Identification is possible thanks to the hypothesis that, for each equation, there is a common heterogeneity component for sisters and that, conditional on this component, sisters' behaviors are otherwise independent. A similar framework has been used by Brien et al. (1999), who estimate the determinants of entry into marriage, cohabitation, and non-marital conception. They model each outcome with a continuous hazard model, and they account for the simultaneity of the three related processes. In this case, they are able to observe multiple episodes of each outcome for a subsample of women, and this allows for the identification of the degree of variation in individual-specific components for each outcome and the correlation among those components. Upchurch, Lillard and Panis (2002) use the same framework to estimate a model where education, marriage, and fertility decisions influence one another and where each outcome is affected by a woman's characteristics. Similarly, Angeles, Guilkey and Mroz (2005) jointly estimate the determinants of education level, age at marriage, and fertility using maximum likelihood procedures that allow the heterogeneity terms of the three equations to be correlated. ${ }^{7}$

We thus follow this strand of literature and we extend the previous analyses by also modeling the hazard of entering the labor market. We believe that a simultaneous equation approach is well suited to capture the interrelationship of the decisions that we model with household survey data. ${ }^{8}$ 


\section{Empirical Strategy}

We model four key decisions in a woman's life course: $(i)$ the level of education, $(i i)$ the age at marriage, (iii) the age at first birth, and (iv) the age of entry in the labor market. The determinants of these four choices are jointly estimated, as some unobservable factors can exert an influence on more than one of the decisions that we model. Our simultaneous equations have a recursive structure, with a function of the outcome of an equation entering as an endogenous regressor in each of the other equations. For instance, we allow the age at first birth, which we model in the third equation, to depend on the completed number of school grades and on the time elapsed since rite of marriage. ${ }^{9}$ The estimation of the fourequation model is discussed after descriptions of each of the equations.

\subsection{Education}

We model the number of grades completed by the women in our sample with an ordered probit model, which represents a common approach in the literature for the analysis of the progression through school. ${ }^{10}$ The ordered probit model allows for grade level to be the outcome of a series of ordered discrete choices - whether to go on to the next grade or withdraw from school. Furthermore, the distribution of years of schooling is, as in most data, not normal around the mean and not unimodal, but instead has peaks representing completion of specific levels such as primary school. As shown in Table 1, there are some mass points, with 33.4 percent of the women having no schooling, and 18.7 percent having dropped out of school at the end of the primary school, which again is better handled by the ordered probit than OLS.

More specifically, we model woman $i$ living in community $j$ who has completed $k$ grades of schooling, i.e. $G_{i j}=k$, if $\mu_{k}<G_{i j}^{*}<\mu_{k+1}$, where $G_{i j}^{*}$ is the latent continuous variable that generates the observed $G_{i j}$, and $\mu_{k}$ and $\mu_{k+1}$ are the cut-off points to be estimated. Equation (1) describes the determinants of the latent variable $G_{i j}^{*}$ 


$$
G_{i j}^{*}=\boldsymbol{\beta}^{G '} \boldsymbol{X}_{i j}^{G}+\varepsilon_{i j}^{G}+\eta_{i j}^{G}
$$

where $\boldsymbol{X}_{i j}^{G}$ is a vector of time-invariant exogenous regressors. This vector includes individual, household-, and community-level variables that are also included in the other three equations, plus some exclusion restrictions. The vector $\boldsymbol{X}_{i j}^{G}$ includes information on age, ethnicity, religion, area of residence, region of birth, level of education of the parents, and on whether the parents died before the time of the survey. ${ }^{11}$ We also include a variable that indicates the presence of a health service within $5 \mathrm{~km}$ from the dwelling. Furthermore, as described more in detail in Section 4 below, we include a synthetic measure of household assets, following the work of Sahn and Stifel (2000, 2003).

The vector also includes information on some salient characteristics of the community, taken from a separately administered set of community questionnaires to leaders of the villages where women live: the distance to the closest phone, the presence of different kinds of microcredit institutions, the availability of electricity and piped water. ${ }^{12}$ The inclusion of several community covariates reduces the likelihood that unobserved community heterogeneity could affect the outcomes observed.

There are also a series of schooling variables that are excluded from the other equations. These include dummies for the presence of primary and secondary schools within a range of $5 \mathrm{~km}$ from the place of residence, and on the professional experience of the teachers and the level of education of the director of the nearest primary school. ${ }^{13}$ The inclusion of controls for some of the characteristics of the community provides credence to the exclusion of these variables from the other equations, as it weakens the concerns that they might be picking up, for example, the effect of the level of local economic development.

Some of the variables are based on retrospective information that refers to the time at which the women in our sample were around 10 years old. Specifically, we use retrospective information $(i)$ on the availability of key infrastructures (i.e., primary and secondary schools 
and health service) within $5 \mathrm{~km}$ of the dwelling and (ii) on the dwelling characteristics (i.e. the type of water source, the type of toilet facility, and the floors material), in order to build the asset index. ${ }^{14}$ This allows us to include in the vector $\boldsymbol{X}_{i j}^{G}$ variables that reflect the household and local conditions that prevailed around the time when the decisions concerning the education of the women in our sample were actually taken. ${ }^{15}$

The term $\varepsilon_{i j}^{G}$ in Equation (1) represents the influence of unobserved characteristics on the number of completed grades and it is assumed to follow a normal distribution; $\eta_{i j}^{G}$ follows an identically and independently distributed normal distribution, i.e., $\eta_{i j}^{G} \underset{\sim}{i i d} N\left(0, \sigma_{G}^{2}\right)$.

\subsection{Marriage}

We model the age at marriage with a proportional hazard model:

$$
\ln h_{i j}^{M}(t)=\boldsymbol{\beta}^{M \prime} \boldsymbol{X}_{i j}^{M}+\alpha_{1}^{M} A g e_{i j}(t)+\alpha_{2}^{M} G_{i}(t)+\varepsilon_{i j}^{M}
$$

where $h_{i j}^{M}(t)$ represents the ratio between the probability of getting married at time $t$ over the cumulative probability of not having married up to time $t ;{ }^{16}$ we assume that the risk of marriage begins at age 11 because 12 years old is the lowest age at marriage declared by women in our sample. We rely on a generalized Gompertz model, which allows the baseline hazard rate to be a non-monotonic function of time; $\operatorname{Age}_{i j}(t)$ is the piecewise linear duration dependency spline, with nodes every three years to allow for a flexible woman- and timespecific impact of time on the log hazard, which we will also denote as $\gamma_{i j t} . G_{i}(t)$ represents the completed number of grades of woman $i$ at time $t$.

The survival function, $S_{i j}^{M}(t)$, which denotes the probability of not having married up to time $t$, is given by:

$$
S_{i j}^{M}(t)=e^{-\int_{0}^{t} h_{i j}^{M}(u) d u}=e^{-\lambda\left(\gamma_{i j t}\right)^{-1}\left(e^{\gamma_{i j t} t}-1\right)}
$$

where $\lambda=e^{\boldsymbol{\beta}^{M}, X_{i j}^{M}+\alpha_{2}^{M} G_{i}(t)+\varepsilon_{i j}^{M}}$. The exclusion restriction for Equation (2) is represented by a variable capturing the tightness of the marriage market, which can influence the likelihood of 
getting married (Becker 1981). This is measured as the ratio of the number of men to the number of women in the same age cohort as woman $i$ at the time of the survey. ${ }^{17}$ The other elements of the vector $\boldsymbol{X}_{i j}^{M}$ are described in Section 3.1 above. $\varepsilon_{i j}^{M}$ captures unobserved heterogeneity, which is assumed, as in Brien and Lillard (1994), to follow a normal distribution, possibly correlated with the unobserved heterogeneity of the other three equations. $^{18}$

\subsection{Age at first birth}

The age at first birth is modeled with the hazard model described in Equation (3):

$$
\ln h_{i j}^{P}(t)=\boldsymbol{\beta}^{P}{ }^{\prime} \boldsymbol{X}_{i j}^{P}+\alpha_{1}^{P} A g e_{i j}(t)+\alpha_{2}^{P} G_{i}(t)+\alpha_{3}^{P} \operatorname{Mar}_{i j}(t)+\varepsilon_{i j}^{P}
$$

where $\ln h_{i j}^{P}(t)$ is the log-hazard of parenthood at time $t$. The risk of parenthood begins at age nine because 10 years old is the lowest age at childbearing declared by women in our sample. We include multiple sources of duration dependence in the model, namely $A g e_{i j}(t)$ and $\operatorname{Mar}_{i j}(t)$, with the latter representing the time elapsed since marriage. $A g e_{i j}(t)$ contains a node every three years as in Equation (2), while the coefficient of the marriage duration is allowed to change after three years. The exclusion restrictions are given by the availability of condoms in the community at the time of the survey and by the year when condoms first became available. The other covariates are described above, and $\varepsilon_{i j}^{P}$ represents unobserved heterogeneity, that is assumed to follow a normal distribution.

\subsection{Labor market}

Finally, Equation (4) presents the hazard model for age at entry into the labor market:

$$
\ln h_{i j}^{L}(t)=\boldsymbol{\beta}^{L}{ }^{\prime} \boldsymbol{X}_{i j}^{L}+\alpha_{1}^{L} A g e_{i j}(t)+\alpha_{2}^{L} G_{i}(t)+\alpha_{3}^{L} \operatorname{Mar}_{i j}(t)+\alpha_{4}^{L} \operatorname{Par}_{i j}(t)+\varepsilon_{i j}^{P}
$$

where $\ln h_{i j}^{L}(t)$ is the log-hazard of labor market entry at time $t$. We assume that the risk modeled in Equation (4) begins at the age of five. Beyond the age and the marriage duration spline, the model also includes the term $\operatorname{Par}_{i j}(t)$, which represents the time elapsed since the 
birth of the first child and whose coefficient is allowed to vary after the first two years of motherhood. The exclusion restrictions are dummy variables that indicate if a positive or a negative shock in the labor market occurred after a woman left school. ${ }^{19}$ The other covariates in $\boldsymbol{X}_{i j}^{L}$ are shared with the other equations, and $\varepsilon_{i j}^{L}$ represents unobserved heterogeneity, that is assumed to follow a normal distribution.

\subsection{Estimation}

Individual unobserved heterogeneity poses two main challenges to the estimation of these four interrelated outcomes. Observations with the same values for all covariates are not identical in terms of their hazards: some are more likely to experience failures than others because there are unobservables, $\varepsilon_{i j}$, that influence the decision processes that we are analyzing. The second main challenge is represented by the fact that the unobserved factors that appear in Equations (1)-(4) are likely to be correlated, i.e., the same unobserved individual-specific characteristics simultaneously influence the four decisions we want to model. If this is the case, these influences give rise to an endogeneity problem. Consider, for instance, the time-varying number of completed grades of schooling $G_{i}(t)$ that appear on the

right side of Equations (2)-(4): $G_{i}(t)$ is determined by $\varepsilon_{i j}^{G}$, thus whenever $\operatorname{corr}\left(\varepsilon_{i j}^{G}, \varepsilon_{i j}^{k}\right) \neq 0$, with $k=M, P, L$, then $G_{i}(t)$ will be correlated with the unobserved component in (2)-(4), and $G_{i}(t)$ will thus be an endogenous regressor.

In order to deal with these challenges, we opt for an estimation strategy that is consistent with the fact that the decisions about schooling, marriage, childbearing, and labor market participation are interrelated, and we jointly estimate the four models. We consider these decisions as interrelated, in the sense that they are all influenced by individual characteristics and that some of the endogenous outcomes of interest have a direct impact on other outcomes. Some of these characteristics are observed, while others are unobserved. We assume that, after conditioning on all observed variables, the heterogeneity term captures all 
sources of correlations among the four decision processes. The likelihood functions of each of the four models are independent if we are able to condition for the relevant observed and unobservable characteristics. If this is the case, the joint conditional likelihood of the set of observed outcomes for the four decision processes is the product of the conditional probabilities of the four outcomes.

Identification of our four-equation system requires adding some structure on unobservable factors. Ideally, if we were able to repeatedly observe the choices made by a single woman under different observable conditions, as in Brien et al. (1999), we could control for the invariant unobserved heterogeneity since we could "estimate the degree of variation in woman-specific component for each of the four processes and the correlation among those components" (Brien et al., 1999, 540). Our data do not allow for such an ideal setting, so we need to introduce assumptions which allow us to identify the covariance matrix of unobserved heterogeneity components. Since we do not have repeated outcomes for the same individual, we assume that all the sisters living in the same household share identical heterogeneity components for each equation, as in Brien and Lillard (1994). This is a reasonable hypothesis since sisters are exposed to the same family circumstances and come from the same background, i.e., the same social context and the same value system. ${ }^{20} \mathrm{We}$ also assume that, conditional on this common heterogeneity component, the behavior of sisters is otherwise independent. These identifying assumptions allow for the estimation of the degree of variation in the sisters-specific component for each process and the correlation among these components. ${ }^{21}$ Generally speaking, the presence of a sub-sample of sisters allows us to observe the outcomes of the four processes under different observables but identical unobservable conditions. As observed by Brien and Lillard (1994) the replication represented by sisters allows us to identify the sibling-specific heterogeneity components. ${ }^{22}$ 
Estimation of the model is based on the maximization of the following joint marginal likelihood $L$ :

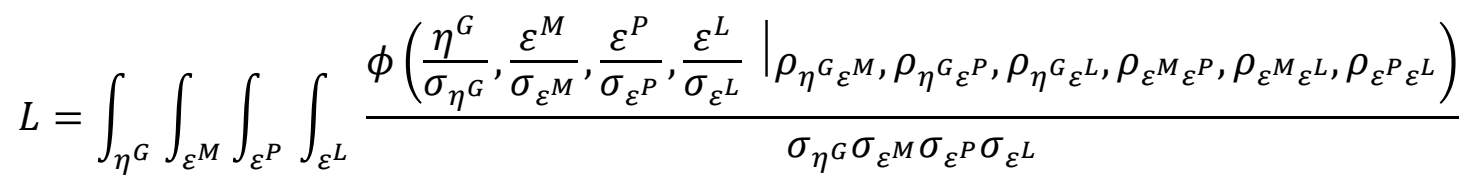

$$
\begin{aligned}
& \times \prod_{\lambda=1}^{N s i s}\left(L_{\lambda}^{G}\left(\eta^{G}\right) L_{\lambda}^{M}\left(\varepsilon^{M}\right) L_{\lambda}^{P}\left(\varepsilon^{P}\right) L_{\lambda}^{L}\left(\varepsilon^{L}\right)\right) d \eta^{G} d \varepsilon^{M} d \varepsilon^{P} d \varepsilon^{L}
\end{aligned}
$$

where $L_{\lambda}^{G}\left(\eta^{G}\right), L_{\lambda}^{M}\left(\varepsilon^{M}\right), L_{\lambda}^{P}\left(\varepsilon^{P}\right)$ and $L_{\lambda}^{L}\left(\varepsilon^{L}\right)$ are the individual conditional probabilities for sibling $\lambda$ and Nsis is the household-specific number of sisters. ${ }^{23}$

Lillard $(1993,195)$ points out that the model described above requires no further identifying restrictions (e.g., exclusion restrictions on exogenous covariates), since conditional on the residual heterogeneity components, the observed completed durations and outcomes are independent. Nonetheless, Lillard also notes that such restrictions may be desirable if such variables can be found, so each equation contains exclusion restrictions, i.e., covariates that are included only in one equation and are excluded from the others. ${ }^{24}$ The software we use for this analysis is aML (Lillard and Panis 2000).

\subsection{Marginal effects}

Since our four-equation system is recursive, the computation of the marginal effects of any regressor needs to account for both the direct effect in each of the four models, as well as for the indirect effects that go through the outcomes of earlier models.

Let $\boldsymbol{Z}_{i j}$ denote all the regressors which are included in at least one of the four equations; without loss of generality, assume that the first element in the vector $\boldsymbol{Z}_{1 i j}$ is a continuous variable. ${ }^{25}$ The partial derivative of the predicted number of completed grades $E\left(G \mid Z_{i j}\right)$, with respect to $Z_{1 i j}$, is given by: 


$$
\frac{\partial E\left(G \mid \boldsymbol{Z}_{i j}\right)}{\partial X_{1 i j}}=\sum_{k=0}^{N} \frac{\partial \operatorname{Prob}\left(G=k \mid \boldsymbol{Z}_{i j}\right)}{\partial X_{1 i j}} k=\sum_{k=0}^{N} \beta_{1}^{G} \phi\left(\mu_{k}-\boldsymbol{\beta} \mathbf{Z}_{\mathrm{ij}}^{\mathrm{G}}\right)
$$

Then, we compute the impact of the marginal variation in $\boldsymbol{Z}_{1 i j}$ upon the median age at marriage, ${ }^{26}$ as predicted by the duration model in Equation (2). This, in turn, depends on (i) the direct impact captured by the estimated coefficient in Equation (2); and (ii) the impact which goes through the influence of the variation in $E\left(G \mid \boldsymbol{Z}_{i j}\right)$.

Similarly, the influence of a marginal variation in $\boldsymbol{Z}_{i j}$ upon the parenthood model in Equation (3) has to account for its influence upon the timing of the marriage. To give an idea of the richness of these indirect effects, we can observe that the influence of, say, the death of the father upon the age of entry in the labor market of a woman in the sample depends on 17 coefficients estimated in the four models. We provide in Section 5 below the point estimates of the direct and the total marginal effects. ${ }^{27}$

\section{Data sources and descriptive statistics}

The data we use in this paper is from the 2003 Household Survey on Education and Welfare in Senegal, conducted in 33 rural and 30 urban communities. ${ }^{28}$ Although, as discussed by Glick and Sahn $(2009,2010)$ the EMBS 2003 sample is not truly nationally representative, it is part of a cohort study of young children, and efforts were made to ensure that it is as close as possible to a random sample. Indications from comparisons with other national surveys indicate that this effort was quite successful, and that the sample of 1,820 households is representative of the population in terms of religions, ethnic groups, demographic characteristics, and other characteristics such as education.

In our analysis, we rely extensively on the education, labor market, and demographic modules of the EMBS 2003, as well as the module that contains information on the current residence, and on retrospective information for adults above age 21 about the household and community characteristics when they were around 10 years old. ${ }^{29}$ We also use the community 
and school modules that collect detailed information on the local infrastructure in general, as well as about the characteristics of schools in the community. This includes the experience and credentials of the principal and management of the school, as well as the number of teachers, their qualifications, and pedagogical practices. Furthermore, we have information about the availability of family planning services and contraceptives, which were collected through a community questionnaire, and on the time when these services and contraceptives were introduced in the community.

Our sub-sample consists of 2,668 women aged 15 to 30 at the time of the survey, with 1,011 women having at least one sister living in the same household. ${ }^{30}$ Specifically, we regard two women as sisters on the basis of their relationship with the household head, as the dataset does not provide us with a matrix of all the bilateral relationships between each pair of household members. Hence, our definition of sisters also includes half-sisters. All women are included in the analysis, although the distribution of the unobserved heterogeneity is identified out of the variation in the outcomes of the sub-sample of women with at least one sister. $^{31}$

Women in our sample have on average 4.11 years of schooling, and the distribution of the number of completed grades is presented in Table 1. Thirty two percent of the women in the sample are married, 24 percent have at least one child, and 21 percent are married with a child. The mean age at marriage is 18.2 years, while the mean age at first birth stands at 19.5. Birth before marriage occurs for approximately 10 percent of the women who have a child. ${ }^{32}$ Just half of them got married within two years after childbearing, so that we can assume that childbearing has a direct effect on marriage decision only for about 1.3 percent of the sample. This is why we decided not to consider this effect in our model.

Childbearing before dropping out of school is not common, as only 10 women in our sample had a child no later than the year in which they left school, and only seven women 
had a child in the following year. This suggests that the direct effect of childbearing on schooling is negligible in our sample, and it justifies the recursive structure of our model.

Around 18 percent of our sample report working in the labor market, where the average age at entry stands at 16.5 years. We define the labor market as comprising entrepreneurs and employees, both in the private and public sectors, thus not including unpaid workers in household enterprises and apprentices.

Descriptive statistics for the variables used in this paper are reported in Table 1A. The average age of women in our sample is 20.5 years. Only 37 percent of their fathers and 24 percent of their mothers attended some school. Twenty-two and seven percent of the women's fathers and mother, respectively, died before the survey. Urban and rural areas are almost equally represented in our data. Ninety percent of the women lived within $5 \mathrm{~km}$ of a primary school at young ages, while only 61 percent lived within $5 \mathrm{~km}$ from a lower secondary school, and 81 percent lived within $5 \mathrm{~km}$ of a health service. Among other community infrastructure, approximately four out of five communities have piped water and have readily available condoms, with the average year that condoms became locally available being 1994. The mean distance to the nearest fixed telephone is $1.1 \mathrm{~km}$, and around 43 percent of women live in communities where more than $75 \%$ of households use electricity. Approximately 60 percent of the communities report having access to at least one of the following types of credit sources: micro-credit, insurance, or individual lenders. Around half of the sample of women experienced a positive economic shock in the community where they live after having left school, while negative shocks occurred for 57 percent of them.

\section{Estimates}

We present the results of the four-equation model in Table 2 and 3, where we report the coefficients and the standard errors of the joint estimation. We provide both direct 
marginal effects and the total effects operating through the endogenous variables of the key explanatory variables on the four outcomes in Tables 4 and 5 .

\subsection{Education}

We find that the educations of mothers and fathers have a powerful impact on schooling attainment of their daughters. Interestingly, the magnitude of the coefficients of the father's education is higher than that of the mother. When we compute the marginal effects, we find that if the mother completed primary school, the daughter is estimated to have completed 0.67 additional years of school. If the mother completed at least lower secondary school, the predicted effect on schooling of the daughter just about doubles to 1.42 years of schooling. The impact of a father's education is much greater; a daughter of a father who has completed primary school will have 1.22 additional years of schooling, with the comparable number years of lower secondary schooling being 1.98 more years for his daughter, as compared to having a father with no schooling. ${ }^{33}$ The death of a father reduces the expected years of schooling by about 0.44 years; no such effect is observed for the death of a mother, as indicated by the insignificant point estimate. ${ }^{34}$ One plausible explanation for this is that the father's death has a greater impact on household resources and thus contributes to an earlier school dropout.

The asset index also has the expected positive association with schooling outcomes. A child at schooling age, living in a dwelling within $5 \mathrm{~km}$ of a primary school, is expected to have completed 2.8 more years of school than a child without such proximity. The presence of a lower secondary school within $5 \mathrm{~km}$ has about one-third the impact on schooling as the presence of a primary school. Our results indicate that a 10-percentage point increase in teachers with at least five years of experience raises the expected years of schooling by 0.07 years. $^{35}$

\subsection{Marriage}


One of the most notable results of the marriage model is that 3.5 additional years of schooling, corresponding to one standard deviation increase, delay the median age at marriage by approximately 2.15 years. ${ }^{36}$ We also find that a woman's mother having some education increases the survival probabilities of the woman in the non-marital state, and the death of a mother has the opposite effect, raising the hazard of entering into marriage. More specifically, median survival time to marriage among women in our sample is increased by 4.27 years when their mothers have primary education, while the death of a mother reduces the survival time by nearly two years. The total effects are higher than the direct effects because of the indirect influence of mother's education and death that passes through the number of completed grades. Interestingly, we find little direct effect of a father's death and education on the hazard of marriage. However, we can observe that a father's death and education have a positive and significant effect on own education, and own education has a significant effect in delaying marriage, so we can conclude that the effect of a father's death and education on the timing of marriage passes through their influence on the number of completed grades. ${ }^{37} \mathrm{We}$ also find that the higher the ratio of men to women, the higher the hazard of getting married. This is consistent with our expectations insofar as the more men relative to women in the local marriage market, the shorter is the median survival time to marriage. $^{38}$

\subsection{First birth}

In modeling the hazard of first birth, we find that the coefficients on the time since marriage, as entered as a spline for the first three years, has the expected positive sign and is statistically significant at standard levels, while the spline for the additional years of marriage is not significant. This can be interpreted as suggesting that the hazard of having a first birth increases with time during the first three years of marriage, and thereafter, it remains stable. 
In terms of the magnitude of the impact, delaying marriage by one year (i.e., decreasing marriage duration by one year) increases the median age at first child by 0.64 years. ${ }^{39}$

We observe that woman's own education, as well as her parents' education, are not significant. Despite this, education still has a role in shaping decisions about the timing of first birth; the effect passes through the delay of marriage, as discussed above. In Table 5, we can see that, when computing the total marginal effect, 3.5 additional grades of education, corresponding to one standard deviation, delay age at first birth by 1.25 years.

The death of a woman's mother has a significant direct impact on the hazard of first birth, reducing the median survival time to first birth by 2.5 years. If we look at the total effect, its impact is magnified due to the effect that passes through the marriage decision. The death of a father also has a significant direct impact on the timing of first birth, although the effect is smaller than the death of a mother.

We also find that the availability of condoms and related family planning facilities in the community reduces the hazard of first birth. In those communities where condoms have been recently introduced, the median survival time to first birth is higher. This might be explained by the fact that there is a greater influence in the period which shortly follows the introduction of condoms, both because of their novelty, as well as the possibility that more recent efforts at condom diffusion are more effective in terms of broad-based behavioral change. $^{40}$

Table 2 (panel C) shows that most of the other covariates that we include in the parenthood model are not significant. This is not an unexpected result, given the high explanatory power of the marriage duration spline. The correlation between age at marriage and age at first child is 0.63 and the difference between the two ranges between zero and three years for 70 percent of the married women who had a child. If we run our 4-equation 
model omitting the marriage duration spline, several covariates in the first child model turn out to be significant. ${ }^{41}$

\subsection{Labor market entry}

A woman's own education does not have a significant direct effect on the hazard of entering the labor market. This is somewhat expected since education is likely to exert two opposing influences on labor market entry, delaying entry of women, who leave the school later and who might queue longer in anticipation of a better wage offer, while at the same time contributing to earlier entry due to employers being more willing to hire women with better credentials. ${ }^{42}$ Our model suggests that the impact of grade attainment on the risk of labor market entry passes through the influence of schooling on the timing of marriage and parenthood (see below). Having 3.5 additional years of schooling decreases the median survival time to labor market entry by 0.53 years.

If we look at the direct effect of parents' education on the hazard of entering the labor market, we notice that only the women whose parents have completed the college experience a significant increase in the median survival time to labor market entry. This can be presumably explained by their willingness to wait for better job offers. The effect of lower levels of parents' education essentially passes through marriage delay: a higher level of parents' education is associated with a delay in marriage, which, in turn, reduces the mean survival time to labor market entry. The death of a mother or a father does not have a significant direct effect on the timing of labor market entry, but they indirectly contribute to earlier entry into the labor market through their effect on the other outcomes.

We also consider how the time elapsed since marriage affects the entry into the labor market. The negative and significant effect of being married for $0-3$ years indicates that the hazard of entering the labor market (the change in the instantaneous probability) decreases during the first three years of marriage; thereafter, marriage duration has no impact on the 
hazard of working outside the home. In terms of magnitude, delaying marriage by one year reduces the expected time before entering the labor market by 0.27 years. The negative coefficients of the motherhood duration splines also suggest that the hazard of entering the labor market decreases in the first two years of motherhood, although, the effect is not statistically significant. ${ }^{43,44}$

The hazard of entering the labor market increases as a result of a positive economic shock having occurred after leaving school. Presumably, this reflects the better opportunities for paid employment that are associated with positive economic events that occur when a woman has exited school. Conversely, any change in the hazard of entering the labor market is not affected by negative shocks that occur after leaving school. This result seems plausible since a negative shock would be expected to increase the impetus for a woman to find a job to cope with the stress of the shock, but at the same time, a negative covariate shock may reduce the possibilities of finding such a job.

\subsection{Heterogeneity correlations}

Finally, in Table 3, we present the standard deviations and correlations of the heterogeneity components. All of the standard deviations are significant, meaning that the sisters-specific heterogeneity component is significant across the four processes. The correlation between marriage and parenthood is positive and highly significant. This indicates that women with a propensity to delay marriage do so, similarly, with the decision to have a first birth, and this correlation persists once we control for the direct effect of the marriage duration on the age at first birth and for all the other covariates.

The correlations between the other heterogeneity components are not statistically significant. ${ }^{45}$ This suggests that the richness of our dataset allows us to control for covariates that are able to simultaneously determine the outcomes of interest. In light of this result, we also run the model ignoring the correlations between the heterogeneity components, to see if 
the results are different once we treat schooling, marriage, and childbearing as exogenous variables in the other models. Table 6 presents the coefficients of the key variables for the model without heterogeneity. When we restrict the correlation across equations to zero, the results are not substantially different. But the magnitude and the significance of some key coefficients vary, and the standard errors are generally lower. In particular, the magnitude of the coefficients of the marriage duration spline in the parenthood model is larger, and the marriage duration spline for more than three years after marriage is significant. We computed the likelihood ratio test to compare the two models: the test follows a $\chi^{2}(6)$ distribution under the null. The test statistic is 25.72 , meaning that our approach to allowing for the correlations across equations to differ from zero fits the data better. We can conclude, as in Brien and Lillard (1994), that, even if the model that controls for correlation in heterogeneity across equations does not produce dramatically different results from the model that does not control for this correlation, it is still preferred because it both produces consistent estimated parameters and standard errors, and also provides a better overall fit of the data.

\section{Conclusions}

We have simultaneously estimated four key decisions in a woman's life course, $(i)$ the level of education, (ii) the age at marriage, (iii) the age at first birth, and (iv) the age at entry into the labor market, through a recursive model which allows for common unobserved factors and controls for the endogeneities that result from the joint determination of these outcomes. We identified the covariance matrix of unobserved heterogeneity components under the assumption that sisters share identical heterogeneity components for each equation.

Our main goal was to shed some light on the relationships between these four interrelated decisions, with a particular attention to the effect of schooling on the other outcomes that we model. We find that the number of completed grades among young women is important in delaying the age at marriage and at first birth, with this latter effect mainly 
operating through the delay in marriage. This result is consistent with the early findings by Brien and Lillard (1994) and with the recent findings by Duflo et al. (2012) and Kirdar et al. (2009). Although we are not able to fully disentangle the ambiguous direct effect of education on the hazard of labor market entry, we show that education indirectly eases entry into the labor market again through a delay in marriage: having 3.5 additional years of schooling decreases the median survival time to labor market entry by 0.53 years in our sample. Our results also show that marriage and childbearing decisions are simultaneously determined by unobserved factors, as in Brien et al. (1999). The hazard of having a first birth significantly increases during the first three years of marriage, while the opposite is observed for the hazard of entering the labor market. Delaying marriage by one year increases the median age at first child by 0.64 years, while it reduces the median age at entry in the labor market by 0.27 years.

We also aimed to gain some insight into the role of family background in shaping the four outcomes that we model. With this respect, we highlight the importance of parents' education, the death of a father and the wealth of the parents' household on educational outcomes. We also show that the education of a young woman's mother delays marriage, while her mother's death has just the opposite effect; the effect of the corresponding variables for the father essentially passes through their influence on the number of completed grades. Parental education affects the timing of first birth and of entering the labor market mostly indirectly through the delay of marriage. Finally, the death of the parents has an important effect in terms of contributing to an early timing of first birth, while it only indirectly affects the hazard of entering the labor market. ${ }^{46}$

Our findings provide some important insights into the policy objective of improving the opportunities and well-being of women in Senegal, a country with large gender disparities 
in education and work and where early marriage and low age at first birth is common. Most development interventions designed to prevent early childbearing aim at changing sexual behaviors through increasing contraception use or through education programs focused on avoiding risking behaviors and unwanted pregnancy. Our results however, lend support not only to those policy interventions, but also to policies aimed at reducing early marriage, directly, as would be the case of laws that ban marriage of very young girls, or indirectly through, for example, cash transfers programs (Baird et al. 2010; Baird et al. 2011). Our results thus encourage researchers to focus their attention at gaining a better understanding of which policies can effectively delay the age at marriage, and thus the age at childbearing, as doing so will facilitate labor market entry, and more generally will promote greater opportunities for young women.

Finally, we acknowledge that some of our results, notably the ones on the size of the estimated effects, are hard to generalize to other countries, particularly outside West Africa, and time periods. We therefore encourage further research in this area, covering the breath of potential methodological approaches. These may range from the type of simultaneous systems approach we employ, to randomized control trials, that for example, contribute to delays in marriage, in order to determine how doing so shape the transition of young women into the labor market. 


\section{References}

Abramitzky, R., Delavande, A., and Vasconcelos, L. 2011. "Marrying Up: the Role of Sex Ratio in Assortative Matching." American Economic Journal: Applied Economics 3(3): $124-157$.

Ainsworth, M., Beegle, K. and Nyamete, A.1996. "The Impact of Women's Schooling on Fertility and Contraceptive Use: A Study of Fourteen Sub-Saharan African Countries." World Bank Economic Review 10(1): 85-122.

Angeles, G., Guilkey, D.K., and Mroz, T.A. 1998. "Purposive Program Placement and the Estimation of Family Planning Program Effects in Tanzania." Journal of the American Statistical Association 93(443): 884-899.

Angeles, G., Guilkey, D.K., and Mroz, T.A. 2005. "The effects of education and family planning programs on fertility in Indonesia." Economic Development and Cultural Change 54(1): 165-201.

Angrist, J. 2002. "How Do Sex Ratios Affect Marriage And Labor Markets? Evidence from America's Second Generation.” Quarterly Journal of Economics 117(3): 997-1038. Angrist, J., and Evans, W. 1998. "Children and their parents' labor supply: Evidence from exogenous variation in family size." American Economic Review 88(3): 450-477.

Appleton, S. 1996. "How does female education affect fertility? A structural model for the Côte d'Ivoire." Oxford Bulletin of Economics and Statistics 58(1): 139-166.

Assaad, R., and Zouari, S. 2003. "Estimating the impact of marriage and fertility on the female labor force participation when decisions are interrelated: Evidence from urban Morocco." In Topics in Middle Eastern and North African Economies Vol. 5, ed. E. M. Cinar. Chicago: Middle East Economic Association and Loyola University Chicago. Bailey, M.J. 2006. 'More power to the pill: The impact of contraceptive freedom on women's lifecycle labor supply." Quarterly Journal of Economics 121(1): 289-320. 
Baird, S., McIntosh C. and Özler. B. 2011. "Cash or condition? Evidence from a Randomized Cash Transfer Program.” Quarterly Journal of Economics 126(4): 1709-1753.

Baird, S., Chirwa E., McIntosh C. and Özler. 2010. "The Short-Term Impacts of a Schooling Conditional Cash Transfer Program on the Sexual Behavior of Young Women." Health Economics 19: 55-68.

Baizàn, P., Aassve A., and Billari, F. 2003. "Cohabitation, Marriage and First Birth: The Interrelationship of Family Formation Events in Spain". European Journal of Population 19(2): 147-169.

Becker, Gary S. 1981. A Treatise on the Family. Cambridge: Harvard University Press.

Beegle, K. and Krutikova, S. 2007. “Adult Mortality and Children’s Transition into Marriage”. World Bank Policy Research Working Paper 4139.

Breierova, L. and Duflo, E. 2004. "The Impact of Education on Fertility and Child Mortality: Do Fathers Really Matter Less Than Mothers?” NBER Working Paper N.10513.

Brien, M.J., and Lillard L.A. 1994. "Education, marriage, and first conception in Malaysia." Journal of Human Resources 29(4): 1167-1204.

Brien, M.J., Lillard, L.A., and Waite, L.J. 1999. "Cohabitation, marriage and nonmarital conception.” Demography 36(4): 535-551.

Browning, M. 1992. "Children and household economic behavior.” Journal of Economic Literature 30(3): 1434-1475.

Bourguignon F., Ferreira F.H.G. and P.G. Leite. 2003. “Conditional Cash Transfers, Schooling, and Child Labor: Micro-Simulating Brazil's Bolsa Escola Program”. The World Bank Economic Review 17(2): 229-254.

Cameron, L.A., Dowling, J.M., and Worswick, C. 2001. "Education and labor market participation of women in Asia: Evidence from five countries." Economic Development and Cultural Change 49(3): 459-477. 
Chun, H., and Oh, J. 2002. "An instrumental variable estimate of the effect of fertility on the labour force participation of married women.” Applied Economics Letters 9(10): 631634.

Coppola, L. 2004. "Education and Union Formation as Simultaneous Processes in Italy and Spain.” European Journal of Population 20(3): 219-250.

Duflo, E., Dupas, P. and Kremer, M. 2012. "Education, HIV, and Early Fertility: Experimental Evidence from Kenya". Unpublished manuscript.

Dumas, C. and Lambert, S. 2011. "Educational Achievement and Socio-economic Background: Causality and Mechanisms in Senegal”. Journal of African Economies 20(1): 1-26.

Fafchamps, M. and Shilpi, F. 2014. "Education and Household Welfare”. Economic Development and Cultural Change 63(1), pp. 73-115.

Field, E. and Ambrus, A. 2008. "Early Marriage, and Female Schooling Attainment in Bangladesh”. Journal of Political Economy 116(5): 881-930.

Glewwe, P., and Jacoby, H. 1994. "Student Achievement and Schooling Choice in LowIncome Countries: Evidence from Ghana.” Journal of Human Resources 29(3): 843-864.

Glick P., Handy, C., and Sahn, D.E. 2011. "Schooling, marriage and childbearing in Madagascar." Cornell Food and Nutrition Policy Program Working Paper No.241, Cornell University, Ithaca, NY.

Glick, P., and Sahn, D.E. 2000. "Schooling of girls and boys in a West African country: the effects of parental education, income, and household structure." Economics of Education Review 19(1): 63-87. 
Glick, P., and Sahn, D.E. 2009. “Cognitive skills among children in Senegal: Disentangling the roles of schooling and family background." Economics of Education Review 28(2): $178-188$.

Glick, P., and Sahn, D.E. 2010 "Early academic performance, grade repetition, and school attainment in Senegal: A panel data analysis.” World Bank Economic Review 24(1): 93120.

Gourieroux, C., Monfort, A., Renault, E., and Trognon, A. 1987. “Generalized Residuals.” Journal of Econometrics 34(1-2): 5-32.

Güneş P. M. 2013. “The Impact of Female Education on Fertility: Evidence from Turkey”. GCC Working Paper Series, GCC 13-01.

Heckman, J.J., and Singer, B. 1984. "A method for minimizing the impact of distributional assumptions in econometric models for duration data." Econometrica 52(2): 271-320.

Heckman, J.J., and Willis, R. 1975. "Estimation of a stochastic model of reproduction: An econometric approach." In Household Production and Consumption, ed. N. Terleckyi. New York: Columbia University Press.

Holmes, J. 2003. "Measuring the determinants of school completion in Pakistan: analysis of censoring and selection bias." Economics of Education Review 22(3): 249-264.

Hotz, V.J., and Miller, R. 1988. “An empirical analysis of life cycle fertility and female labor supply." Econometrica 56(1): 91-118.

Jensen, R. 2012. "Do Labor Market Opportunities Affect Young Women's Work and Family Decisions? Experimental Evidence from India." Quarterly Journal of Economics 127: 753-792.

Kim, L., and Aassve, A. 2006. "Fertility and its consequences on family labour supply." IZA Discussion Papers No. 2162, Bonn. 
Kirdar, M. G., Tayfur M. D. and Koç, İ. 2009. "The Impact of Schooling on the Timing of Marriage and Fertility: Evidence from a Change in Compulsory Schooling Law". Department of Economics, Middle East Technical University, Ankara.

Kruger, D.I., Soares, R.R., and Berthelon, M. 2012. "Household choices of child labor and schooling: A simple model with application to Brazil." Journal of Human Resources 47(1): 1-31.

Lam D, Anderson K. 2002. "Women's schooling, fertility, and investments in children in South Africa." Paper presented at the annual meeting of the Population Association of America. Atlanta, GA.

Levison, D., Moe, K.S., and Knaul, F.M. 2001. "Youth education and work in Mexico." World Development 29(1): 167-188.

Lillard, L.A. 1993. "Simultaneous equations for hazards. Marriage duration and fertility timing." Journal of Econometrics 56(1-2): 189-217.

Lillard, L. and King, E. 1984. "Methods for analyzing schooling choice with household survey data." Rand Note N-1963-AID, Santa Monica: Rand Corporation.

Lillard, L.A. and Panis, C.W.A. 2000. aML Multiprocess Multilevel Statistical Software Release 1. Los Angeles: EconWare.

Lillard, L.A. and Willis, R.J. 1994. "Intergenerational educational mobility: Effects of family and state in Malaysia." Journal of Human Resources 29(4): 1126-1166.

Mahy M. and Gupta N. 2001. "Trends and differentials in age at first birth in Sub-Saharan Africa". Unpublished manuscript. Demographic and Health Research Division, ORC Macro International: Calverton, MD.

Maitra, P., 2003. "Schooling and Educational Attainment: Evidence from Bangladesh." Education Economics 11(2): 129-153. 
Maitra, P., and Ray, R. 2002. "The joint estimation of child participation in schooling and employment: Comparative evidence from three continents." Oxford Development Studies 30(1): 41-62.

Mason, K.O. 1986. "The status of women: Conceptual and methodological debates in demographic studies.” Sociological Forum 1(2): 284-300.

McKenzie, D.J., and Rapoport, H. 2011. "Can migration reduce educational attainment? Evidence from Mexico.” Journal of Population Economics 24(4): 1331-1358.

Mensch B.S., Singh S., Casterline J.B. 2005. "Trends in the timing of first marriage among men and women in the developing world". In The Changing Transitions to Adulthood in Developing Countries: Selected Studies, ed. Lloyd C.B., Behrman J.R., Stromquist N.P. and Cohen B. National Academies Press: Washington, DC.

Michel, R.T. and Tuma, N.B. 1985. "Entry Into Marriage and Parenthood by Young Men and Women: The Influence of Family Background”. Demography 22(4): 515-544.

Moffit, R. 1984. "Profiles of fertility, labour supply and wages of married women: A complete life- cycle model." Review of Economic Studies 51(2): 263-278.

Mroz, T.A. 1999. "Discrete factor approximations in simultaneous equation models: Estimating the impact of a dummy endogenous variable on a continuous outcome." Journal of Econometrics 92(2): 233-274.

Mroz, T.A., and Guilkey, D.K. 1995. "Discrete factor approximations for use in simultaneous equation models with both continuous and discrete endogenous variables." Working Paper 95-02, Department of Economics, University of North Carolina at Chapel Hill, NC. Osili, U.O., and Long, B.T. 2008. "Does female schooling reduce fertility? Evidence from Nigeria.” Journal of Development Economics 87(1): 57-75. 
Palermo, T. and Peterman, A. 2009. “Are Female Orphans at Risk for Early Marriage, Early Sexual Debut, and Teen Pregnancy? Evidence from Sub-Saharan Africa”. Studies in Family Planning 40(2): 101-112.

Pörtner, C.C., Beegle, K., and Christiaensen, L. 2011. Family planning and fertility:

Estimating program effects using cross-sectional data. Paper presented at CSAE 25 th Anniversary Conference 2011: Economic Development in Africa, Oxford, March 20-22. Ray, R. 2002. "The determinants of child labour and child schooling in Ghana." Journal of African Economies 11(4): 561-590.

Rosenzweig, M., and Schultz, T.P. 1985. "The demand for and supply of births: Fertility and its life cycle consequences." American Economic Review 75(5): 992-1015.

Sahn D.E. and Stifel D.C. 2000. "Poverty comparisons over time and across countries in Africa." World Development 28(12): 2123-2155.

Sahn D.E. and Stifel D.C. 2003. "Exploring alternative measures of welfare in the absence of expenditure data." Review of Income and Wealth 49(4): 463-489.

Sakamoto, A., and Powers, D.A. 2006. "Demography of Social Stratification.” In Handbook of Population, ed. D.L. Poston and M. Micklin. New York: Kluwer Academic/Plenum Publishers, springeronline.com.

Schultz, T. P. 1993. "Returns to Women's Education," in Women's Education in Developing Countries: Barriers, Benefits, and Policies, ed. E. M. King and M. A. Hill. Johns Hopkins University Press.

Schultz, T.P. 1994. "Studying the impact of household economic and community variables on child mortality." Population and Development Review 10 (Suppl.): 215-235.

Terza, J.V., Basu, A., and Rathouz, P. 2008. "Two-stage residual inclusion estimation: Addressing endogeneity in health econometric modeling." Journal of Health Economics 27(3): 531-543. 
Thomas, D., and Maluccio, J. 1996. "Fertility, contraceptive choice, and public policy in Zimbabwe." World Bank Economic Review 10(1): 189-222.

Upchurch, D.M., Lillard, L.A., and Panis, C.W. 2002. "Nonmarital childbearing: Influences of education, marriage, and fertility." Demography 39(2): 311-329.

US Department of State. 2009. Human Rights Report: Senegal. Bureau of Democracy, Human Rights, and Labor, Washington DC.

Wahba, J. 2006. "The influence of market wages and parental history on child labour and schooling in Egypt.” Journal of Population Economics 19(4): 823-852.

Waite, L.J., and Stolzenberg, R.M. 1976. "Intended childbearing and labor force participation of young women: Insights from nonrecursive models.” American Sociological Review 41(2): 235-252.

Younger, S.D. 2006. "Labor market activities and fertility." Cornell Food and Nutrition Policy Program Working Paper No. 218, Cornell University, Ithaca, NY. 
Table 1. Distribution of the completed grades of schooling

$\begin{array}{cccc}\begin{array}{c}\text { Completed } \\ \text { grades }\end{array} & \text { Frequency } & \text { Percent } & \text { Cumulative } \\ 0 & 891 & 33.40 & 33.40 \\ 1 & 22 & 0.82 & 34.22 \\ 2 & 50 & 1.87 & 36.09 \\ 3 & 120 & 4.50 & 40.59 \\ 4 & 220 & 8.25 & 48.84 \\ 5 & 300 & 11.24 & 60.08 \\ 6 & 499 & 18.70 & 78.79 \\ 7 & 148 & 5.55 & 84.33 \\ 8 & 104 & 3.90 & 88.23 \\ 9 & 114 & 4.27 & 92.50 \\ 10 & 89 & 3.34 & 95.84 \\ 11 & 29 & 1.09 & 96.93 \\ 12 & 38 & 1.42 & 98.35 \\ 13 & 40 & 1.50 & 99.85 \\ 14 & 4 & 0.15 & 100.0 \\ \text { Total } & 2,668 & 100.00 & \\ \text { Source: Authors' elaboration on EMBS } 2003 .\end{array}$


Table 2. Joint estimation results. Panel A: Completed Grades

Variables

Age

Muslim

Father dead

Mother dead

Father education, some primary

Father education, completed primary

Father education, completed college

Mother education, some primary

Mother education, completed primary

Mother education, completed college

Asset index

Rural area

Distance to telephone

Electricity

Pipeline network

Health service

Credit, micro-credit institution

Credit, insurance

Credit, individual lender

Primary school

College

School director schooling

Teachers' experience

$\begin{array}{cc}\text { coefficient } & \text { s.e. } \\ -0.01 * & (0.01) \\ -0.42 * * * & (0.15) \\ -0.21 * * * & (0.07) \\ 0.00 & (0.12) \\ 0.23 * & (0.13) \\ 0.55 * * * & (0.09) \\ 0.88^{* * *} & (0.11) \\ 0.01 & (0.13) \\ 0.31 * * * & (0.10) \\ 0.64 * * * & (0.14) \\ 0.01 * * * & (0.00) \\ 0.43 * & (0.26) \\ -0.02 & (0.02) \\ 0.11 & (0.09) \\ 0.36 * * * & (0.12) \\ 0.00 & (0.10) \\ -0.04 & (0.14) \\ 0.22 & (0.14) \\ 0.43 * * & (0.18) \\ 1.51 * * * & (0.13) \\ 0.43 * * * & (0.08) \\ 0.02 & (0.02) \\ 0.31 * & (0.18) \\ & \end{array}$

2,688

$-12,145.71$

Log-likelihood

Note: Asymptotic standard errors in parentheses; ${ }^{* *}, * *$, and $*$ denote significance at the 1, 5, and 10 percent level, respectively; the set of regressors also includes dummies for six ethnic groups and 11 Senegalese regions (coefficients not reported).

Source: Authors' elaboration on EMBS 2003. 
Table 2. Joint estimation results.

Panel B: Age at marriage

\begin{tabular}{|c|c|c|}
\hline Variable & coeffiecient & s.e. \\
\hline Age 11 & $-14.13^{* * *}$ & $(38.05)$ \\
\hline Age 11 to 14 & $1.31 * * *$ & $(0.23)$ \\
\hline Age 14 to 17 & $0.55^{* * *}$ & $(0.07)$ \\
\hline Age 17 to 20 & $0.34 * * *$ & $(0.06)$ \\
\hline Age 20 to 23 & $0.13^{*}$ & $(0.07)$ \\
\hline Age 23 to 26 & $0.24 * *$ & $(0.10)$ \\
\hline Age 26 and above & 0.15 & $(0.16)$ \\
\hline Age & $0.12 * *$ & $(0.05)$ \\
\hline Grade completed & $-0.14 * * *$ & $(0.04)$ \\
\hline Muslim & $0.87 *$ & $(0.46)$ \\
\hline Father dead & -0.03 & $(0.13)$ \\
\hline Mother dead & $0.54 * * *$ & $(0.20)$ \\
\hline Father education, some primary & -0.22 & $(0.32)$ \\
\hline Father education, completed primary & -0.24 & $(0.21)$ \\
\hline Father education, completed college & -0.22 & $(0.26)$ \\
\hline Mother education, some primary & $-1.00 * * *$ & $(0.30)$ \\
\hline Mother education, completed primary & $-0.67 * *$ & $(0.28)$ \\
\hline Mother education, completed college & $-0.90 * *$ & $(0.40)$ \\
\hline Asset index & 0.00 & $(0.00)$ \\
\hline Rural area & 0.55 & $(0.49)$ \\
\hline Distance to telephone & $0.06^{* *}$ & $(0.02)$ \\
\hline Electricity & -0.21 & $(0.18)$ \\
\hline Pipeline network & $-0.44 * *$ & $(0.19)$ \\
\hline Health service & -0.21 & $(0.15)$ \\
\hline Credit, micro-credit institution & -0.12 & $(0.25)$ \\
\hline Credit, insurance & -0.38 & $(0.25)$ \\
\hline Credit, individual lender & 0.02 & $(0.29)$ \\
\hline Men to women ratio & $3.63^{* *}$ & $(1.62)$ \\
\hline Observations & 2,688 & \\
\hline Log-likelihood & $-12,145.71$ & \\
\hline \multicolumn{3}{|c|}{$\begin{array}{l}\text { Note: Asymptotic standard errors in parentheses; } * * * * * \text {, and } * \text { denot } \\
\text { significance at the } 1,5 \text {, and } 10 \text { percent level, respectively; the set } 0 \\
\text { regressors also includes dummies for six ethnic groups and } 1 \\
\text { Senegalese regions (coefficients not reported). }\end{array}$} \\
\hline
\end{tabular}

Source: Authors' elaboration on EMBS 2003. 
Table 2. Joint estimation results. Panel C: Age at first child

\begin{tabular}{|c|c|c|}
\hline Variables & coefficient & s.e. \\
\hline Age 9 & $91.24 * *$ & $(38.05)$ \\
\hline Age 9 to 12 & 0.07 & $(0.54)$ \\
\hline Age 12 to 15 & $0.82 * * *$ & $(0.23)$ \\
\hline Age 15 to 18 & $0.35 * * *$ & $(0.11)$ \\
\hline Age 18 to 21 & $0.50 * * *$ & $(0.08)$ \\
\hline Age 21 to 24 & 0.05 & $(0.09)$ \\
\hline Age 24 to 27 & 0.09 & $(0.13)$ \\
\hline Age 27 and above & 0.11 & $(0.27)$ \\
\hline Marriage duration intercept & $1.53 * * *$ & $(0.25)$ \\
\hline Marriage duration, 0 to 3 years & $0.96 * * *$ & $(0.12)$ \\
\hline Marriage duration, 3 years and above & 0.09 & $(0.07)$ \\
\hline Age & 0.01 & $(0.02)$ \\
\hline Grade completed & -0.04 & $(0.05)$ \\
\hline Muslim & -0.16 & $(0.56)$ \\
\hline Father dead & $0.57 * * *$ & $(0.19)$ \\
\hline Mother dead & $0.48^{*}$ & $(0.26)$ \\
\hline Father education, some primary & -0.05 & $(0.52)$ \\
\hline Father education, completed primary & 0.48 & $(0.32)$ \\
\hline Father education, completed college & 0.11 & $(0.40)$ \\
\hline Mother education, some primary & 0.30 & $(0.44)$ \\
\hline Mother education, completed primary & 0.33 & $(0.44)$ \\
\hline Mother education, completed college & -0.37 & $(0.74)$ \\
\hline Asset index & 0.00 & $(0.00)$ \\
\hline Rural area & 0.43 & $(0.73)$ \\
\hline Distance to telephone & 0.03 & $(0.04)$ \\
\hline Electricity & $-0.54 * *$ & $(0.26)$ \\
\hline Pipeline network & $-0.69 * *$ & $(0.33)$ \\
\hline Health service & -0.33 & $(0.23)$ \\
\hline Credit, micro-credit institution & 0.61 & $(0.40)$ \\
\hline Credit, insurance & -0.01 & $(0.40)$ \\
\hline Credit, individual lender & 0.31 & $(0.48)$ \\
\hline Year condoms were first available & $-0.05 * * *$ & $(0.02)$ \\
\hline Condoms available & $-0.71 * *$ & $(0.32)$ \\
\hline Observations & 2,688 & \\
\hline Log-likelihood & $-12,145.71$ & \\
\hline \multicolumn{3}{|c|}{$\begin{array}{l}\text { Note: Asymptotic standard errors in parentheses; } * * *, * * \text {, and } * \text { denote } \\
\text { significance at the } 1,5 \text {, and } 10 \text { percent level, respectively; the set of } \\
\text { regressors also includes dummies for six ethnic groups and } 11\end{array}$} \\
\hline
\end{tabular}

Source: Authors' elaboration on EMBS 2003. 
Table 2. Joint estimation results.

Panel D: Age at entry in the labor market

\begin{tabular}{|c|c|c|}
\hline Variables & coefficient & s.e. \\
\hline Age 5 & $-8.68 * * *$ & $(1.15)$ \\
\hline Age 5 to 8 & 0.11 & $(0.23)$ \\
\hline Age 8 to 11 & $0.30 * *$ & $(0.15)$ \\
\hline Age 11 to 14 & $0.32 * * *$ & $(0.10)$ \\
\hline Age 14 to 17 & $0.20 * *$ & $(0.09)$ \\
\hline Age 17 to 20 & $0.19 * *$ & $(0.09)$ \\
\hline Age 20 to 23 & 0.15 & $(0.11)$ \\
\hline Age 23 to 26 & 0.18 & $(0.13)$ \\
\hline Age 26 and above & $0.44 * * *$ & $(0.16)$ \\
\hline Marriage duration intercept & $0.56^{*}$ & $(0.30)$ \\
\hline Marriage duration, 0 to 3 years & $-0.37 * *$ & $(0.18)$ \\
\hline Marriage duration, 3 years and above & -0.06 & $(0.08)$ \\
\hline Motherhood duration intercept & -0.12 & $(0.77)$ \\
\hline Motherhood duration, 0 to 2 years & -0.26 & $(0.94)$ \\
\hline Motherhood duration 2 years and above & 0.02 & $(0.07)$ \\
\hline Age & $-0.04 *$ & $(0.02)$ \\
\hline Grade completed & 0.03 & $(0.04)$ \\
\hline Muslim & -0.30 & $(0.36)$ \\
\hline Father dead & 0.20 & $(0.17)$ \\
\hline Mother dead & 0.35 & $(0.25)$ \\
\hline Father education, some primary & 0.39 & $(0.34)$ \\
\hline Father education, completed primary & 0.06 & $(0.23)$ \\
\hline Father education, completed college & $-0.56^{*}$ & $(0.33)$ \\
\hline Mother education, some primary & -0.15 & $(0.35)$ \\
\hline Mother education, completed primary & 0.11 & $(0.29)$ \\
\hline Mother education, completed college & $-0.85^{*}$ & $(0.51)$ \\
\hline Asset index & 0.00 & $(0.00)$ \\
\hline Rural area & $1.90 * * *$ & $(0.55)$ \\
\hline Distance to telephone & 0.04 & $(0.03)$ \\
\hline Electricity & 0.25 & $(0.24)$ \\
\hline Pipeline network & $-0.57 * *$ & $(0.27)$ \\
\hline Health service & -0.23 & $(0.19)$ \\
\hline Credit, micro-credit institution & 0.53 & $(0.32)$ \\
\hline Credit, insurance & $0.92 * * *$ & $(0.34)$ \\
\hline Credit, individual lender & $0.89 * *$ & $(0.36)$ \\
\hline Positive shock 0 to 3 years & $0.74 * *$ & $(0.29)$ \\
\hline Positive shock 3 to 6 years & $0.98 * * *$ & $(0.29)$ \\
\hline Positive shock 6 years and above & $0.67 * * *$ & $(0.22)$ \\
\hline Negative shock 0 to 3 years & 0.04 & $(0.42)$ \\
\hline Negative shock 3 to 6 years & 0.33 & $(0.31)$ \\
\hline Negative shock 6 years and above & -0.14 & $(0.21)$ \\
\hline
\end{tabular}


Note: Asymptotic standard errors in parentheses;***, **, and * denote significance at the 1,5 , and 10 percent level, respectively; the set of regressors also includes dummies for six ethnic groups and 11 Senegalese regions (coefficients not reported).

Source: Authors' elaboration on EMBS 2003

Table 3. Variance-covariance matrix of unobserved heterogeneity

$\begin{array}{lcccc} & \begin{array}{c}\text { Schooling } \\ 0.69 * * *\end{array} & \text { Marriage } & \text { Parenthood } & \text { Labor } \\ \text { Schooling } & (0.07) & & & \\ & 0.05 & 1.33^{* * *} & & \\ \text { Marriage } & (0.14) & (0.14) & & \\ & -0.06 & 0.30^{* * *} & 2.22 * * * & \\ \text { Parenthood } & (0.12) & (0.07) & (0.23) & 1.59 * * * \\ & -0.07 & 0.05 & 0.11 & (0.20)\end{array}$

Note: Standard error in parenthesis; ***,**, and * denote significance at the 1,5 , and 10 percent, respectively.

Source: Authors' elaboration on EMBS 2003.

\section{Table 4. School attainment model marginal effects}

$\begin{array}{lcc}\text { Variable } & \begin{array}{c}\text { Marginal } \\ \text { effect }\end{array} & \begin{array}{c}\text { Standard } \\ \text { deviation }\end{array} \\ \text { Age } & -0.026 & 0.007 \\ \text { Muslim } & -0.922 & 0.230 \\ \text { Father dead } & -0.444 & 0.128 \\ \text { Mother dead } & -0.006 & 0.002 \\ \text { Father education, some primary } & 0.502 & 0.132 \\ \text { Father education, primary completed } & 1.22 & 0.294 \\ \text { Father education, college completed } & 1.976 & 0.423 \\ \text { Mother education, some primary } & 0.028 & 0.008 \\ \text { Mother education, primary completed } & 0.669 & 0.172 \\ \text { Mother education, college completed } & 1.421 & 0.329 \\ \text { Asset index } & 0.020 & 0.006 \\ \text { Rural area } & 0.887 & 0.273 \\ \text { Primary school } & 2.796 & 0.926 \\ \text { College } & 0.944 & 0.244 \\ \text { School Director schooling } & 0.044 & 0.012 \\ \text { Teachers' experience } & 0.660 & 0.186\end{array}$

Note: Marginal effects are measured in years; the effects for continuous regressors refer to one standard deviation increase, while for dummy variables we report the effect of a discrete change from zero to one; standard deviations in parenthesis.

Source: Authors' elaboration on EMBS 2003. 
Table 5. Marginal effects of selected variables for hazard models

\begin{tabular}{lcccccc} 
Variables & \multicolumn{2}{c}{ Age at marriage } & \multicolumn{2}{c}{ Age at first child } & \multicolumn{2}{c}{$\begin{array}{c}\text { Age at entry in labor } \\
\text { market }\end{array}$} \\
\cline { 2 - 7 } & $\begin{array}{l}\text { Direct } \\
\text { effect }\end{array}$ & Total effect & $\begin{array}{c}\text { Direct } \\
\text { effect }\end{array}$ & Total effect & $\begin{array}{c}\text { Direct } \\
\text { effect }\end{array}$ & $\begin{array}{c}\text { Total effect } \\
\end{array}$ \\
\cline { 2 - 7 } & 0.060 & -0.142 & -2.036 & -3.623 & -0.385 & -0.633 \\
& $(0.667)$ & $(0.724)$ & $(3.378)$ & $(2.017)$ & $(1.113)$ & $(0.959)$ \\
Death of the father & -1.875 & -2.166 & -2.533 & -3.211 & -1.055 & -1.043 \\
& $(1.507)$ & $(1.092)$ & $(2.194)$ & $(1.362)$ & $(1.034)$ & $(0.813)$ \\
Death of the mother & 0.843 & 1.132 & 0.248 & 0.629 & -1.205 & -1.669 \\
& $(0.982)$ & $(0.899)$ & $(0.872)$ & $(0.988)$ & $(1.082)$ & $(1.224)$ \\
Father education, some primary \\
(compared to no education)
\end{tabular}

Note: Marginal effects are measured in years; the effects for continuous regressors refer to one standard deviation increase, while for dummy variables we report the effect of a discrete change from zero to one; standard deviations in parenthesis.

Source: Authors' elaboration on EMBS 2003. 
Table 6. Models with and without heterogeneity

\begin{tabular}{cccc} 
Model with heterogeneity & \multicolumn{2}{c}{$\begin{array}{c}\text { Model without } \\
\text { heterogeneity }\end{array}$} \\
\cline { 2 - 5 } coefficient & s.e. & coefficient & s.e.
\end{tabular}

Age at marriage

Education grade completed

$-0.14 * * * \quad(0.04) \quad-0.13 * * * \quad(0.02)$

\section{Age at first child}

Marriage duration spline, intercept

$\begin{array}{cccc}1.53 * * * & (0.25) & 1.92 * * * & (0.22) \\ 0.96 * * * & (0.12) & 0.97 * * * & (0.11) \\ 0.09 & (0.07) & 0.12 * & (0.06) \\ -0.04 & (0.05) & -0.05 & (0.03)\end{array}$

Marriage duration 0-3 years

Marriage duration 3+ years

Grade completed

$\begin{array}{cccc}0.56^{*} & (0.30) & 0.55^{*} & (0.29) \\ -0.37^{* *} & (0.18) & -0.36^{* *} & (0.17) \\ -0.06 & (0.08) & -0.07 & (0.08) \\ -0.12 & (0.77) & -0.06 & (0.77) \\ -0.26 & (0.94) & -0.24 & (0.93) \\ 0.02 & (0.07) & 0.06 & (0.07) \\ 0.03 & (0.04) & 0.02 & (0.03)\end{array}$

Age at entry in the labor market

Marriage duration spline,

intercept

Marriage duration 0 to 3 years

Marriage duration 3+ years

Motherhood duration spline,

intercept

Motherhood duration, 0 to 2 years

Motherhood duration, 2+ years

Grade completed

Log Likelihood

Note: Standard errors in parenthesis; $* * *, * *$, and $*$ denote significance at the 1,5 , and 10 percent, respectively.

Source: Authors' elaboration on EMBS 2003. 


\section{APPENDIX}

Table 1a. Definitions and descriptive statistics

Variable

Grade completed Married

Age at marriage

Parent

Age at first child

Work

Explanatory Variables

Age

Muslim

Ethnicity, Wolof

Ethnicity, Poular

Ethnicity, Serere

Ethnicity, Dioola

Ethnicity, Mandingue

Father dead

Mother dead

Father has no education

Father education, some primary

Father education,

completed primary

Father education,

completed college

Mother has no education

Mother education, some

primary

Mother education,

completed primary

Mother education,

completed college

Asset index ${ }^{\mathrm{a}}$

Rural area

Distance to telephone

Electricity

Pipeline network

Health Service ${ }^{\mathrm{a}}$

Credit, micro-credit

institution

Credit, insurance

Credit, individual lender

Exclusion Restrictions

Schooling Model

Primary school ${ }^{\mathrm{a}}$

College $^{\mathrm{a}}$

School Director schooling
Description

Mean

s.d.

Number of grades completed

$\begin{array}{ll}4.11 & 3.55\end{array}$

Percentage of married women

$0.32 \quad 0.47$

Age at marriage

Percentage of women having a child

$18.23 \quad 3.58$

$0.24 \quad 0.43$

$19.53 \quad 3.53$

Age at first child

$0.18 \quad 0.38$

$\begin{array}{lll}\text { Age at entry in the labor market } & 16.52 & 5.37\end{array}$

Age at time of the survey

$20.52 \quad 4.5$

Dummy, $=1$ if woman is Muslim

$0.96 \quad 0.21$

Dummy, $=1$ if woman is Wolof

$0.38 \quad 0.49$

$0.20 \quad 0.40$

Dummy, $=1$ if woman is Poular

Dummy, $=1$ if woman is Serere

$0.18 \quad 0.39$

Dummy, $=1$ if woman is Dioola

$0.06 \quad 0.24$

$0.13-0.34$

Dummy, $=1$ if father is dead at time of the survey $\quad 0.22 \quad 0.42$

Dummy, $=1$ if mother is dead at time of the survey $\quad 0.07 \quad 0.26$

Dummy, $=1$ if father has no education $\quad 0.63 \quad 0.48$

Dummy, $=1$ if father has primary education $\quad 0.06 \quad 0.24$

Dummy, $=1$ if father has completed primary $\quad 0.16 \quad 0.36$

Dummy, $=1$ if father has completed college $\quad 0.15 \quad 0.35$

Dummy, $=1$ if mother has no education $\quad 0.76 \quad 0.42$

Dummy, $=1$ if mother has primary education $\quad 0.07 \quad 0.26$

Dummy, $=1$ if mother has completed primary $\quad 0.12 \quad 0.31$

Dummy, $=1$ if mother has completed college $\quad 0.05 \quad 0.22$

Household asset index, obtained through PCA $\quad 46.63 \quad 23.58$

Dummy, $=1$ if woman lives in a rural area $\quad 0.48 \quad 0.50$

Distance to the telephone from the community, in km $\quad 1.10 \quad 2.78$

Dummy, $=1$ if more than $75 \%$ of households in the community $0.43 \quad 0.49$

use electricity 0.82

Dummy, $=1$ if there is an health service within $5 \mathrm{~km}$ from $\quad 0.81 \quad 0.40$

dwelling

Dummy, $=1$ if a micro-credit institution is present in the $\quad 0.61 \quad 0.49$

community

Dummy, $=1$ if an insurance is present in the community $\quad 0.60 \quad 0.49$

Dummy, $=1$ if an individual lender is present in the $\quad 0.57 \quad 0.50$

community

$0.90 \quad 0.30$

$0.61 \quad 0.49$

$13.33 \quad 1.59$ 
Teachers' experience

\section{Marriage model}

Men to women ratio

\section{Parenthood model}

Condoms available

Year condoms first available

Labor Market model

No Positive shock

Positive shock, $0-3$ years

Positive shock, 3-6 years

Positive shock, 6 years and above

No negative shock

Negative shock, $0-3$ years

Negative shock, 3-6 years

Negative shock, 6 years and above

Percentage of teachers with at least 5 years of experience in the primary school of the community where woman lives at the time of the survey

Ratio of the number of men to the number of women living in the same community and being in the same age cohort as the woman

Dummy, $=1$ if condoms are available in the community where woman lives

$0.80 \quad 0.40$

Year in which condoms were first available in the community where woman lives

$1994 \quad 7.33$

Dummy, $=1$ if there was no positive economic shock in the community where woman lives after she left school

Dummy, $=1$ if there was a positive economic shock in the

community where woman lives, from 0 to 3 years after she left

0.09

Dummy, $=1$ if there was a positive economic shock in the

community where woman lives, from 3 to 6 years after she left

schoo

Dummy, $=1$ if there was a positive economic shock in the community where woman lives, more than 6 years after she left school

Dummy, $=1$ if there was no negative economic shock in the community where woman lives after she left school

0.50

Dummy, $=1$ if there was a negative economic shock in the

0.04

school

Dummy, $=1$ if there was a negative economic shock in the

school

Dummy, $=1$ if there was a negative economic shock in the community where woman lives, more than 6 years after she left school

Note: The descriptive statistics are computed on the sample of 2,268 women used in the analysis. We report the mean value for continuous variables and the percentage of women for which the variable is equal to 1 for dummy variables. ${ }^{\text {aThe }}$ variable is computed at around age ten for individuals aged 21 and above, while it is computed at the time of the survey for women aged less than 21 .

Source: Authors' Elaboration on EMBS 2003.

\footnotetext{
${ }^{1}$ Many authors have observed that such a result usually emerges only for high levels of education for African countries (Younger 2006; Lam and Anderson 2002; Ainsworth, Beegle, and Nyamete 1996; Appleton 1996;

Thomas and Maluccio 1996; Schultz, 1993)

${ }^{2}$ Observe that we model age at first child, while we do not analyze the number of child or the timing of the following pregnancies.

${ }^{3}$ Waite and Stolzenberg (1976) first hypothesized the existence of a simultaneous reciprocal causation between fertility expectations and labor force participation; according to them, there are background factors that
} 
completely account for this relationship. Browning (1992) provides an excellent review of the early papers that tackled the issue of the possible endogeneity of fertility in the analysis of the determinants of labor supply. ${ }^{4}$ The relationship between fertility and female labor supply has also been studied through life-cycle models (Hotz and Miller 1988; Heckman and Willis 1975; Moffit 1984).

${ }^{5}$ Duflo et al. (2012) show that school uniforms' provision reduces by $20 \%$ the likelihood to being married and by $17 \%$ the likelihood of being pregnant three years after the program implementation. Baird et al. (2010) use a cash transfer, conditional upon school attendance, as a treatment and they register a significant decline in the risk of early marriage and early childbearing, an effect that might be due to education or to the positive income effect produced by the transfer. Baird et al. (2011) demonstrate that the income channel is particularly important, showing that the effect of an unconditional cash transfer on delaying marriage and childbearing is relevant only for the girls who dropped out school.

${ }^{6}$ This model is a combination of the simultaneous equations for hazard models by Lillard (1993) and the sequential choice model of education by Lillard and Willis (1994).

${ }^{7}$ The joint distribution of the unobservables is incorporated using a semi-parametric discrete factor method, as suggested by Heckman and Singer (1984) and extended by Mroz and Guilkey (1995) and by Mroz (1999).

${ }^{8}$ Simultaneous equations approaches have been used to model the determinants and the interaction of women's choices also by Baizàn, Aassve and Billari (2003) and Coppola (2004). Baizàn et al. (2003) test whether the timing of first union and first birth is determined by joint factors, while Coppola (2004) uses simultaneous hazard model to analyze the relationship between exit from education and union formation. Additionally, simultaneous models have been extensively used to model the impact of schooling and labor supply decisions of children, under the hypothesis that education and work represent competing claims on the use of the time of the child (Ray 2002; Maitra and Ray 2002; Kruger, Soares and Berthelon 2012; Levison, Moe and Knaul 2001; Wahba 2006). Conversely, when analyzing the relationship between education and labor market participation for young women, the literature usually maintains the assumption that women make their choices with respect to the labor market after having acquired the desired schooling level (Cameron, Dowling and Worswick 2001). ${ }^{9}$ Some arguments that support the recursive structure of the model are presented in Section 5.

${ }^{10} \mathrm{We}$ also considered the option of estimating a hazard model for schooling, but two factors induced us not to do so. First, Senegal is characterized by a substantial incidence of grade repetition, with 28.8 percent of the women in our sample having repeated at least one grade at college, and 67.6 percent of them having done so 
while attending primary school. Hence, two women that left school after an identical number of years could have completed a different number of grades, thus diluting the information that is actually contained in the duration of the time in school. Second, 33.6 percent of the women in our sample did not go to school, so we must also separately model the decision to enroll before modeling the hazard of dropping out of school. The use of an ordered probit model was first proposed by Lillard and King (1984) and then used in a number of studies, including Glick and Sahn (2000, 2010), Glewwe and Jacoby (1994), McKenzie and Rapoport (2011), Maitra (2003), and Holmes (2003).

${ }^{11}$ The household questionnaire of the EMBS 2003 survey contains information on the year of death of the parents, but this information is actually missing for a large share of orphans in our sample. This is why this information has not been used in the econometric analysis.

${ }^{12}$ Access to credit will reduce the probability of early school withdrawal in the face of economic shocks or income constraints; and electricity can allow children to do their homework after the sunset. Similarly, clean water and health clinics reduce the likelihood of disease and infection that would contribute to school absence, withdrawal and poor academic performance.

${ }^{13}$ We provide a more detailed description of the variables included in vector $\boldsymbol{X}_{i j}^{G}$ in Table 1A and in Section 4.

${ }^{14}$ Regrettably, these retrospective questions are asked only to the individuals aged 21 and above. For individuals less than 21 , we use the same information collected at the time of the survey. For this group of women, it is more reasonable to make the hypothesis that the explanatory variables remained constant from the time when parents made education decisions for the women up to the time of the survey.

${ }^{15} \mathrm{We}$ acknowledge that a greater availability of time-varying information would have added credence to the identification of the determinants of education, possibly through a different econometric model such as the sequential probit adopted by Brien and Lillard (1994); regrettably, the EMBS 2003 survey contains individual retrospective information on only a limited set of variables.

${ }^{16}$ The choice of estimating a continuous rather than a discrete time duration model has been driven by the constraints imposed by aML, the software that we use for the estimation of our four-equation model.

${ }^{17}$ The cohort of a woman of age $s$ is defined as ranging between $s-5$ and $s+20$, and we computed them separately for urban and for rural areas. We selected these age intervals following Abramitzky, Delavande and Vasconcelos (2011) and Glick, Handy and Sahn (2011), although we acknowledge that there is not a shared consensus in the literature on the definition of the sex ratio. For instance, Angrist (2002) uses age intervals of 15 
years, with the interval for males being shifted by two years in order to account for the difference in the average age at the time of the wedding of the groom and the bride. We have explored several different age intervals to select the cohort that define the potential marriage market, and the results are not sensitive to this choice. Specifically, the results are robust to the adoption of narrower age ranges, and when we introduce a nine-year difference in the age interval for men and for women, which represents the median age difference between the two spouses in our sample. The robustness of our results with respect to this change also adds credence to the exclusion restriction, as Senegalese women are more likely to compete on the local labor market with men of the same age rather than with older men.

${ }^{18}$ The variance-covariance matrix of unobserved heterogeneity will be estimated with a Gauss-Hermite approximation with six support points.

${ }^{19}$ The fact that the shocks occurred after a woman leaves school provides credence to the exclusion of these variables from the equation on completed grades. The shocks are not self-reported, but come from a community questionnaire administered to village leaders. Positive economic shocks include the establishment of a new enterprise, a sustained period of good rainfall, the building of a new road, and the establishment of an electric plant, of an irrigation system, of a piped water system, or of another development project. The negative economic shocks include a fire, a flood, a period of drought, massive damage to the harvest or to the livestock, or the closure of an important enterprise in the village.

${ }^{20}$ Our estimation strategy is consistent with theoretical models where the parents make differential investments in their children as far as the individual characteristics that drive parental choices are either observed or correlated with their observed characteristics; unobservable child-specific characteristics, such as innate ability, cannot be accommodated in our estimation framework, as we are implicitly assuming that parents make, conditional upon observed individual variables, identical investments in their daughters. This represents a limitation of the estimation approach that we adopt.

${ }^{21}$ The shared unobserved heterogeneity component is a random effect, and this raises the question of the consistency of the estimates if this happens to be correlated with the regressors. This might occur if, for instance, parental education is correlated with the parental concern toward their children that could influence the time and effort that they devote to the schooling of their daughters. Unfortunately, the empirical relevance of this concern cannot be tested, as there is no way to estimate the model that would produce consistent, though not efficient, estimates even in the presence of correlation between the random effect and the regressors. 
${ }^{22}$ The distribution of the unobserved heterogeneity is thus identified out of the variation in the outcomes of the sub-sample of the women with at least one sister. Observe that we do not have all sisters in our sample, but only the ones living in the same household. It is possible that some women have sisters but they are considered as 'singletons' in our analysis because their sisters do not live with them. Consider this woman as a 'singleton' simply means that she does not share the family-specific heterogeneity component with other individuals in the sample.

${ }^{23}$ For further details see appendix A in Brien and Lillard (1994).

${ }^{24} \mathrm{We}$ have also run the model without the exclusion restrictions. The estimated coefficients are not statistically different across the two models (with the exception of the intercept of the first child model). We computed the likelihood ratio test to compare the two models: the test follows a $\chi^{2}(13)$ distribution under the null; the test statistic is 262.8 , and it strongly rejects the null, suggesting that the model with the exclusion restrictions fits the data better.

${ }^{25}$ If one element of this vector is excluded from model $h$ with $h=G, M, P, L$, then its coefficient is constrained to zero.

${ }^{26}$ This is defined as the predicted age at marriage at which $S_{i j}^{M}(t)$ is equal to 0.5 ; no closed form expression exists for the mean time to failure predicted by a Gompertz model.

${ }^{27}$ We follow a standard, though not fully satisfactory, approach in the literature of reporting the point estimates of the marginal effects without the associated standard errors.

${ }^{28}$ See Glick and Sahn $(2009,2010)$ and Dumas and Lambert (2011) for details about the survey design. The questionnaires of the EMBS 2003 survey are accessible through the web site http://www.saga.cornell.edu/Senegal EBMS/surveys.html; users may contact David Sahn to obtain access to the data.

${ }^{29}$ We use information related to the availability of key facilities either at the community- or at the householdlevel, as the salience of these facilities reduces the concerns about the recall bias. Similarly, we use a limited set of information concerning the characteristics of the dwelling, namely the type of water source, toilet, and the material of the floor, in the construction of the asset index. The results of our estimates are not sensitive to the exclusion of this variable.

${ }^{30}$ Five hundred thirty-two women in our sample have 1 sister, 294 have two sisters, 112 have three sisters, and 73 have more than three sisters. 
${ }^{31}$ The assumption that sisters share the same unobserved heterogeneity components might be unrealistic for households with a large number of daughters. Only 6.9 percent of the women in our sample belong to households with more than three sisters. A related threat to identification could arise in the presence of a large difference in the years of birth of the sisters, as the unobserved heterogeneity component might be time-varying and "the extent of sibling differences will likely depend on the difference in age as a result of changes that may have occurred in the age interval that separates them" (Sakamoto and Powers, 2006, 398). Hence, we checked the distribution of the age difference between the youngest and the eldest women in each group of sisters. This is not more than five years for 58.2 percent of the women with at least one sister in our sample. This is, in turn, reassuring about the validity of our identifying assumption, as a limited share of the women in our sample belong to households with more than three sisters or are separated by a notable age gap from their sisters. We reestimated our model, either excluding from the sample the women belonging to households with more than three sisters, or excluding from the sample all groups of sisters where the age difference between the youngest and the eldest is more than five years. The results are robust to these sample selection criteria.

${ }^{32}$ Three percent of sample women have a child but are not married.

${ }^{33}$ The inclusion of the asset variable mitigates the concern that the parental education coefficients might be mostly picking up income effects, and as expected, the point estimates of the coefficients for parental education increase once we omit the asset index from the regressors. Moreover, our model also includes a number of community-level variables that are also likely to be (positively) correlated with household income. As a robustness check, we run the model without the parents' education variable to see if the own education effects are sensitive to the exclusion of the parents' education measures. The results of the model are stable with respect to the removal of these variables.

${ }^{34}$ We might have also expected a significant negative effect of a mother's death, as girls might be called upon to take on more household chores.

${ }^{35}$ Among other marginal effects of note is that Muslim women are expected to complete 0.9 less years of schooling that other religious groups, and women belonging to the Diola ethnic group, 0.7 years more than the predominant Wolof ethnic group. Being born in certain regions also lowers schooling achievement. For instance, those from Diourbel complete 0.68 fewer years of schooling, and conversely, those born in Louga complete more schooling than the region of Dakar (results not shown). Living in rural areas raises the expected number of completed grades by 0.89 years, but this is controlling for region, assets, and other characteristics. 
${ }^{36}$ Table 4 reports both direct and total marginal effects of the explanatory variables. When looking at the direct marginal effect of a variable, we can check for the significance of the corresponding coefficient. Caution is necessary when looking at the total marginal effects, since they result from the combination of many coefficients characterized by different significance levels.

${ }^{37}$ Another individual characteristic that seems to be important in terms of directly affecting the marriage hazard is being a Muslim. We do not observe any significant difference between women living in rural and urban areas. Women living in the region of Matam have a higher hazard of marriage with respect to women living in Dakar, while living in the regions of Thies and Ziguinchor decreases the hazard of marriage (results not shown). When we add family size to the model, this plays a significant role with respect to the age at marriage: the hazard of getting married increases with family size. The other coefficients of the marriage model are not affected by the inclusion of this variable. Family size has a non-significant relationship with the three other outcomes of interest.

${ }^{38}$ It is possible that a higher sex ratio has a negative effect on female labor market participation (Angrist 2002). Since we use the sex ratio as an exclusion restriction in the marriage model, we have tested for the existence of such an effect. We do not find an effect of sex ratio on age at entry in the labor market in our sample.

${ }^{39}$ There are 73 women in polygamous marriages in our sample. We ran the model with a dummy variable for women living with polygamous husbands in the first child and labor market models, and both were insignificant.

${ }^{40}$ Condom availability might be endogenous with respect to childbearing, if family planning services are placed in the communities where higher levels of fertility prevail (Angeles, Guilkey and Mroz 1998). We follow Pörtner, Beegle and Christiaensen (2011) and instrument the availability of condoms using, as explanatory variables, the ranking of the Senegalese departments on some key determinants of fertility rate—specifically population size, the rate of urbanization, education, and the immigration rate. We built these rankings using the data from the 2002 population census. The underlying hypothesis is that, while the average characteristics of the department have an impact on the individual fertility decision, the relative position of a department does not affect individual fertility choices, and it can thus represent a valid instrument for the placement decision. We then compute the generalized residuals (Gourieroux et al. 1987) from the first stage, including them as auxiliary regressors in the non-linear first child model together with the endogenous variables (Terza, Basu, and Rathouz 2008). Results show that the generalized residuals are not significant at a conventional confidence level, thus reducing our concerns about the endogeneity of condoms availability. 
${ }^{41}$ This is the case, for instance, for the number of completed grades and the mother's education. These results, which are available from the authors upon request, are in line with Brien and Lillard (1994).

${ }^{42}$ If education reduces the hazard of entry into the labor market because women queue for a higher wage, then more educated women are likely to enter the labor market in a higher paying job. With wage data (ideally, wages at the time of the first employment), we could go beyond modeling the hazard of job entry, and rather modelling the hazard of finding a job with a wage above a certain threshold, i.e., a wage above a certain percentile of the distribution of wages. Defining the labor market outcome in these terms would eliminate the ambiguity about the impact of education. Regrettably, wage data (either retrospective data or data at the time of the survey) are not available in the EMBS 2003, and this prevents us from following this route.

${ }^{43}$ The motherhood splines are not individually significant, but their total effect could be significantly negative.

${ }^{44}$ As with the other models, we include a range of community covariates, largely as control variables. We do take particular note of the impact of accessibility of credit institutions in terms of increasing the hazard of job entry. The hazard of entering the labor market is higher for women living in rural areas and for women living in Dakar with respect to the ones living in the region of Diourbel and St. Louis (results not shown).

${ }^{45}$ Only one correlation, namely between schooling and marriage, is significant in Brien and Lillard (1994).

${ }^{46}$ These results can be compared to the literature that explores the role of parents' characteristics in shaping children's adult transition. Parents' education and their presence in the households are shown to orient the children towards more school and less work (see, inter alia, Ray 2002; Levison, Moe and Knaul 2001; Wahba 2006; Bourguignon, Ferreira and Leite 2003). There is also a small literature that studies the influence of parents' characteristics on timing of marriage and childbearing. In an early work, Michel and Tuma (1985) observe that we can reasonably "expect the likelihood of an early marriage to fall as parents' educational level rises, $[\ldots]$ and to be lower for youths living with both natural parents at age 14" (p. 516). The importance of parents' education in delaying marriage has been recently confirmed by Field and Ambrus (2008) for Bangladesh, while Beegle and Krutikova (2007) and Palermo and Peterman (2009) have explored the relationship between orphanhood and the likelihood of early marriage and childbearing, finding contrasting results. 